\title{
Analysis of the Perceived Thermal Comfort in a Portuguese Secondary School: Methodology and Results
}

\author{
M. A. Campano, A. Pinto, I. Acosta, and C. Muñoz-González
}

\begin{abstract}
This paper presents a methodology to assess the thermal environment in non-university classrooms, using the example of the results obtained from a multipurpose classroom of a Portuguese secondary school during a week of November. According to the defined protocol, both hygrothermal parameter values and thermal assessments were obtained and used for the calculation of both static and adaptive thermal comfort indicators, including Matias' Portuguese adaptive comfort indicator. Occupants perceived a neutral thermal environment (Thermal Sensation Vote, TSV, of -0.03), while their thermal preference was a warmer environment (Thermal Preference Vote, TPV, of $+\mathbf{0 . 6 4}$ ). Female occupants tended to demand a warmer environment during this study, despite their thermal perception was similar to male occupants. Predicted Mean Vote (PMV) was lower than TSV in 0.35 points, so it underestimates occupants' real thermal perception. When occupants' acceptance vote are compared with Adaptive indicators, Matias' obtains similar acceptance values $(80 \%)$ than the occupants' assessments (85 \%), while ASHRAE indicator shows lower values $(27 \%)$. In conclusion, the exposed methodology allows to characterise the thermal comfort level of Iberian non-university classrooms, so further investigation is required.
\end{abstract}

Index Terms-Field experiments, occupant satisfaction, schools, thermal comfort.

\section{INTRODUCTION}

Indoor thermal environment is a very important factor for obtaining both comfort and productivity improve [1]-[3], especially in non-university schools, where pupils spend around $30 \%$ of their time in classrooms during long hours [4]. In addition, since children and teenagers are more sensitive than adults and schools are one of the most common building typologies, this concern becomes more relevant.

In this way, a series of combined studies was carried out on non-university school classrooms in several countries in order to evaluate the thermal sensation of the occupants, both with natural ventilation and HVAC systems. Significant differences were found in classrooms in the United Kingdom and the United States of America between Thermal Sensation Votes (TSV) of young students and that of adults [5]-[8], while Mors et al. [9] observed that Predicted Mean Vote indicator (PMV) [10] underestimated the real thermal

Manuscript received October 21, 2016; revised March 12, 2017. This work was supported in part by the V Internal Research Plan of the Universidad de Sevilla and the TEP-130 research group.

M. A. Campano, I. Acosta, and C. Muñoz-González are with the Department of Building Construction I, Universidad de Sevilla, Spain (e-mail: mcampano@us.es, iacosta@us.es, carmenmgonzalez@us.es).

A. Pinto is with the National Laboratory for Civil Engineering, Lisbon, Portugal (e-mail: apinto@lnec.pt). sensation by over 1.5 points in the 7-points ASHRAE scale [11]. In adittion, adaptive comfort indicators presented higher temperature limits than the expressed by occupants. Furthermore, studies in Northern Italian schools [4], [12]-[14], UK primary schools [15], [16], and Korean nursery schools [17] showed similar results to those of Mors [9]. It is necessary to highlight the work of Teli et al. [15], [16] in elementary schools, since they found that neutral temperature expressed from the mean Thermal Sensation Votes $\left(\mathrm{TSV}_{\text {mean }}\right)$ was close to $4{ }^{\circ} \mathrm{C}$ lower than that estimated by PMV.

In this way, the present work is focused on developing a work methodology to assess the thermal comfort in Portuguese classrooms. It is noteworthy that these spaces tend to be in free-running and naturally ventilated through windows, since although there are HVAC systems in the most of schools of the region of Lisbon, generally consisting of makeup air units through ducts, they usually are not in operation due to the high electrical and maintenance costs, especially with the current economic crisis.

In this regard, and in spite of Predicted Mean Vote (PMV) is the most common indicator used to predict the thermal sensation, it is also known that its reliability for non-air conditioned spaces is called into question [18]. Thus, there is some research to obtain an expectancy factor which corrects the PMV value, even focused on Mediterranean schools [19]; but since PMV indicator is calculated only with psychological parameters and considers occupants just as passive sensors, research has been focused on adaptive comfort. That is why all adaptive indicators [20]-[24] calculated include dynamical interactions, as occupants' control of clothing insulation, operable windows or solar protections.

\section{OBJeCTIVES}

The main objective of this research is to show the methodology used for the characterization of the existing thermal comfort level of multipurpose classrooms in secondary schools (aged 15-18 years) of the region of Lisbon (Portugal), as well as to define the Thermal Sensation Vote (TSV) and the Thermal Preference Vote (TPV) of occupants, depending on their clothing insulation level and gender. To that effect, a classroom of a secondary school is selected as a case of study, developing both on-site measurements and surveys during a week in winter conditions.

As a secondary objective, a comparative is performed between the Thermal Sensation Vote (TSV) plus a direct question on the acceptability of thermal environment, obtained from surveys, and some of the existing main thermal comfort indicators, calculated from measurements, including Predicted Mean Vote (PMV) and ASHRAE adaptive comfort 
indicator. This study also incorporates an adaptive comfort indicator optimized for the climate of the Iberian Peninsula for its comparison.

\section{METHODOLOGY}

The thermal behaviour of the multipurpose classroom is analysed during a normal school week of November $\left(15^{\text {th }}\right.$ to $\left.21^{\text {st }}\right)$. By using both objective parameter measurements and thermal assessment surveys, four possible data collection instances are established on each of the school days: at the beginning of the school day (instant 1), before the midmorning break (instant 2), before the lunch break (instant 3 ) and after the lunch break (instant 4).

A set of thermal indicators is generated from the data collected in order to evaluate the thermal comfort level of this space.

\section{A. Selection of the Case of Study}

The classroom selected for this study is the standard classroom 24 of the "Eça de Queirós" secondary school, which is located in Lisbon (Portugal). This city has Csa conditions according to the Koppen climate classification [25].

This educational facility is owned by the public entity "Parque Escolar" of the Government of Portugal and was designed by the architect Jorge Martins.

The classroom is located on south corner of the second floor of the secondary school. It is in contact with the outside both by its southeast-facing and south-west-facing walls, as well as by its roof. Its northwest-facing inner partition is in contact with the classroom 23 and its northeast-facing inner partition is adjacent to both the corridor and the classroom 25 . Finally, it is located over the teacher's room of the first floor.

Dimensions are $7.00 \mathrm{~m} \times 7.00 \mathrm{~m}$ with a height of $3 \mathrm{~m}$, accommodating 31 tables plus the teacher desk, as can be seen in Fig. 1. Its access is located on the partition in contact with the corridor with a door $0.9 \mathrm{~m} \times 2.10 \mathrm{~m}$ and a ventilation opening above with a free area of $0.15 \mathrm{~m} \times 0.80 \mathrm{~m}$.

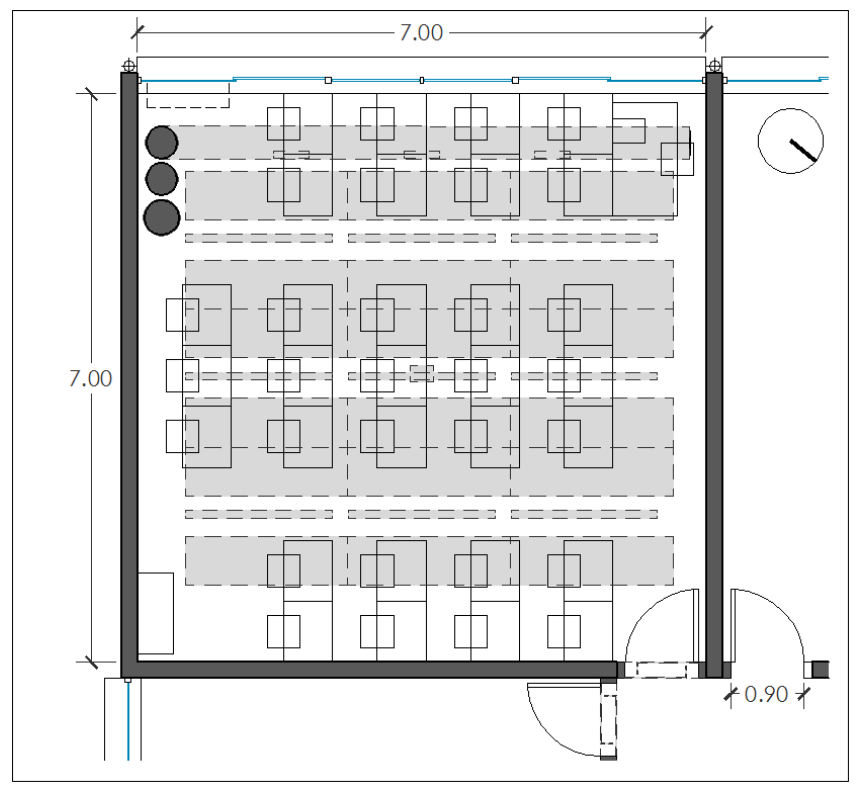

Fig. 1. Plant of the standard classroom 24 of the secondary school.
The composition of the classroom envelope is shown in Table I.

TABLE I: ENVELOPE COMPOSITION OF THE “EÇA DE QUEIRÓS” SCHOO

\begin{tabular}{|c|c|c|}
\hline Element & Composition & $\begin{array}{c}\mathrm{U} \\
\mathrm{W} /\left(\mathrm{m}^{2} \cdot \mathrm{K}\right)\end{array}$ \\
\hline Façade & $\begin{array}{l}\text { Single-layer cement mortar }(1 \mathrm{~cm}) \\
\text { Thermal clay block }(14 \mathrm{~cm}) \\
\text { Air chamber without ventilation }(1 \mathrm{~cm}) \\
\text { Mineral wool }(0.031 \mathrm{~W} / \mathrm{mK}, 2 \mathrm{~cm}) \\
\text { 2x gypsum plasterboard }(1 \mathrm{~cm})\end{array}$ & 0.69 \\
\hline $\begin{array}{l}\text { Vertical } \\
\text { partitions }\end{array}$ & $\begin{array}{l}\text { 2x gypsum plasterboard }(1 \mathrm{~cm}) \\
\text { Air chamber without ventilation }(1 \mathrm{~cm}) \\
\text { Thermal clay block }(14 \mathrm{~cm}) \\
\text { Air chamber without ventilation }(1 \mathrm{~cm}) \\
2 x \text { gypsum plasterboard }(1 \mathrm{~cm})\end{array}$ & 0.96 \\
\hline $\begin{array}{l}\text { Horizontal } \\
\text { partitions }\end{array}$ & $\begin{array}{c}\text { Linoleum }(1 \mathrm{~cm}) \\
\text { Cement mortar }(2 \mathrm{~cm}) ; \text { sand layer }(4 \mathrm{~cm}) \\
\text { Grid slab }(35 \mathrm{~cm})\end{array}$ & 2.4 \\
\hline Roof & $\begin{array}{c}\text { Gravel layer }(5 \mathrm{~cm}) \\
\text { XPS extruded polystyrene }(0.034 \mathrm{~W} / \mathrm{mK}, 5 \\
\mathrm{cm}) \\
\text { Cement mortar }(1 \mathrm{~cm}) \\
\text { Bitumen sheet }(0.5 \mathrm{~cm}) \\
\text { Cement mortar }(1 \mathrm{~cm}) \\
\text { Lightweight aggregate concrete, formation } \\
\text { of slope (mean } 10 \mathrm{~cm}) \\
\text { Grid slab }(35 \mathrm{~cm})\end{array}$ & 0.55 \\
\hline Windows & $\begin{array}{c}6 \mathrm{~mm} \text { single glass pane } \\
\text { Aluminium frame }(2 \mathrm{~cm}) \text { with no thermal } \\
\text { break }\end{array}$ & $\begin{array}{l}5.8 \\
5.9\end{array}$ \\
\hline
\end{tabular}

The classroom is equipped with one desktop PC placed on the teacher's desk, which has an associated projector in the centre of the ceiling of the room. The room has a suspended lighting system of nine fluorescent lamps of $48 \mathrm{~W}$ each, arranged in three rows parallel to the window and levelled with the suspended ceiling, as shows Fig. 2.

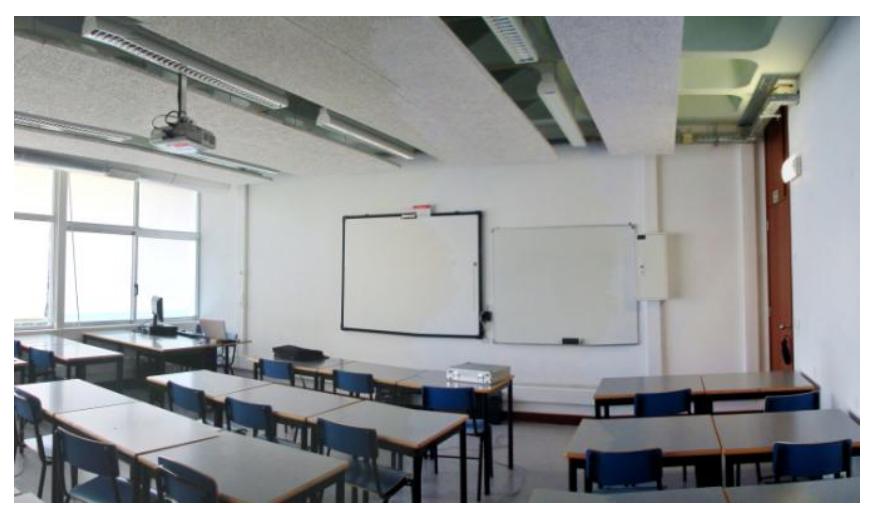

Fig. 2. Inner view of the classroom 24.

The HVAC system of this educational facility consists on a four-pipe hydronic system with one makeup air unit (MAU) for each four classrooms, being located on the roof. These units provide $1100 \mathrm{~m}^{3} / \mathrm{h}$ of outside air to each classroom through $300 \mathrm{~mm}$ diameter individual galvanized sheet metal ducts arranged over the window, as can be seen in Fig. 3. 
Three double deflection grilles of $0.10 \times 0.05 \mathrm{~m}$ are located on this, disposed with an angle of $45^{\circ}$. Air extraction is developed through an air passage over the door. Thus, the ventilation efficiency in cooling mode is 1.0 , while in heating is 0.8 (CR 1752:1998 [26]).

\section{B. Measurement of the Objective Parameters}

A measurement of the physical parameters relating to thermal comfort is carried out in multiple locations, both outdoor and indoor, as can be seen in Fig. 3 [27], [28]:

Indoor measurements:

- "A" Points: Array of 3x2 measurement points (in the desk aisles) at two heights $(0.60$ and $1.50 \mathrm{~m})$.

- Air temperature.

- Relative air humidity.

- Air Velocity.

- "B" Points: 17 surface measurement points on the inner side of vertical partitions.

- Surface temperature.

- "C" Point: 1 surface measurement points on the inner side of the window.

- Surface temperature.

- "S" Point: 1 surface measurement points on the floor.

- Surface temperature.

- "T" Point: 1 surface measurement points on the ceiling.

- Point A5-1:

-Surface temperature.

- Mean radiant temperature.

Outdoor measurements:

- Air temperature.

- Relative air humidity.

- Air velocity.

- Thermography.

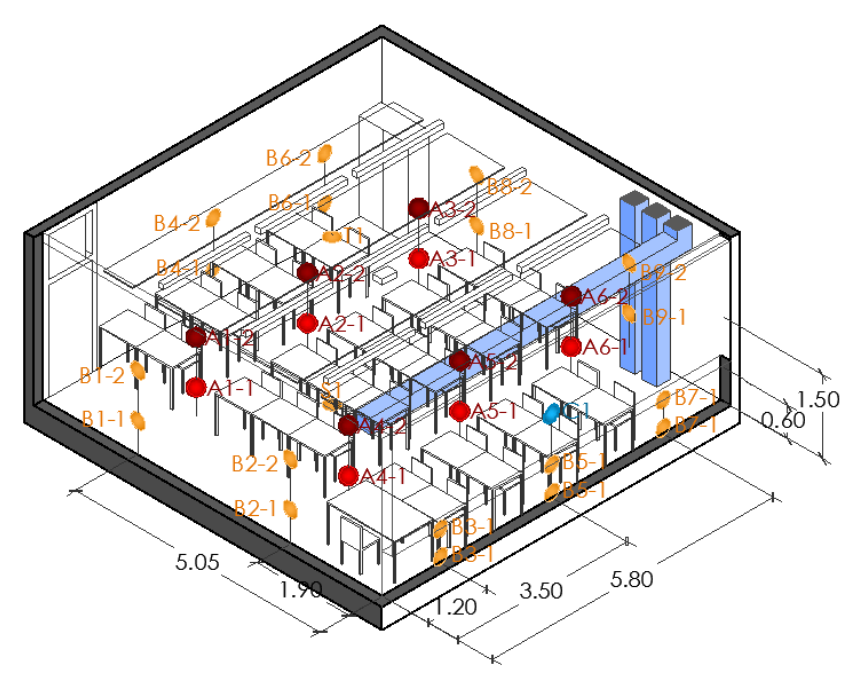

Fig. 3. Array of measurements in the classroom under study.

Detailed information on characteristics of instruments used is presented in Table II, according to ISO 7726 standard [29]. The mean radiant temperature for each location is obtained through a computer simulation, which follows the method described in Appendix B of this ISO 7726 standard [29]. It uses the 19 surface temperature values measured (Fig. 3) plus the mean skin temperature of the occupants and the distance between all these and the referred point with its incidence angle, taking into account the presence of furniture. This calculation is also validated by comparing the results obtained per season with the globe thermometer in point $5 \mathrm{~A}-1$.

TABLE II: CHARACTERISTICS OF THE SENSORS USED

\begin{tabular}{|c|c|c|c|}
\hline Parameter & Units & Sensor & Uncertainty \\
\hline Air temperature & {$\left[{ }^{\circ} \mathrm{C}\right]$} & Testo 0635.1535 (PT100) & $\pm 0.3^{\circ} \mathrm{C}$ \\
\hline $\begin{array}{l}\text { Radiant } \\
\text { temperature }\end{array}$ & {$\left[{ }^{\circ} \mathrm{C}\right]$} & $\begin{array}{c}\text { Testo } 0602.0743 \text { (Globe } \\
\text { probe) }\end{array}$ & $\pm 0.3^{\circ} \mathrm{C}$ \\
\hline $\begin{array}{l}\text { Surface } \\
\text { temperature }\end{array}$ & {$\left[{ }^{\circ} \mathrm{C}\right]$} & $\begin{array}{c}\text { Testo 0602.0393 } \\
\text { (Thermocouple type K) }\end{array}$ & $\pm 0.3^{\circ} \mathrm{C}$ \\
\hline Air velocity sensor & {$[\mathrm{m} / \mathrm{s}]$} & Testo 0635.1535 (Hot wire) & $\pm 0.03 \mathrm{~m} / \mathrm{s}$ \\
\hline Relative humidity & [\%] & $\begin{array}{c}\text { Testo } 0635.1535 \\
\text { (Capacitive) }\end{array}$ & $\pm 2 \%$ \\
\hline Data Logger & - & Data Logger Testo 435-2 & - \\
\hline
\end{tabular}

\section{Distribution of Thermal Comfort Surveys}

During the measurement of the thermal parameters, anonymous thermal comfort surveys were distributed to obtain the occupants' thermal assessments and the clothing worn. The values analysed are:

- Gender and age.

- Thermal Sensation Vote (TSV): from -3 (cold) to +3 (hot) through 0 (neither cold nor hot), using the 7-points ASHRAE scale.

- Thermal comfort level: from 0 (comfortable) to -4 (extremely uncomfortable).

- Thermal Preference Vote (TPV): from -3 (a lot colder) a +3 (a lot warmer) through 0 (neutral).

- Vertical air temperature gradient sensation: Cold feet (yes/no) and hot face (yes/no).

- Acceptance of the thermal environment: yes/no.

- Clothing worn: Compilation of clothing elements with their insulation value, in clo.

- Occupant location in the classroom: A 4x5 cell grid is superimposed on the classroom floor plan, in order to divide it into work sectors, allowing the occupants to show their location and link their assessments to the closest environmental measurement point (at two heights).

A total of 194 students were surveyed during the measurements on site, as can be seen in Table III.

TABLE III: STATISTICAL DATA OF STUDENTS SURVEYED

\begin{tabular}{lccc}
\hline \hline & Students & Per lesson & Percentage \\
\hline Students surveyed & 194 & 17.64 & - \\
Male students surveyed & 102 & 9.27 & $52.6 \%$ \\
Female students surveyed & 92 & 8.36 & $47.4 \%$ \\
\hline \hline
\end{tabular}

\section{Thermal Comfort Indicators}

Objective data obtained from environmental measurements and insulation clothing level are analysed using statistics and a series of thermal comfort indicators. This is in compliance with the recommendations of ISO 7243:1989 [30], EN ISO 7730 [31] and EN ISO 11079 [32] standards on Ergonomics of the thermal environment, and are the following:

- Operative temperature [33].

- Fanger method [10] (static comfort indicators): 
-Predicted Mean Vote (PMV).

- Predicted Percentage of Dissatisfied (PPD).

- Required clothing insulation (IREQ) [32]:

-Maintaining thermal equilibrium with high physiological response (IREQ minimum $_{\text {) }}$.

-Maintaining thermal equilibrium without physiological response (IREQ neutral $_{\text {) }}$.

- Adaptive comfort indicators:

- ASHRAE adaptive comfort indicator [23].

- Matias' adaptive comfort indicator [34, 35], developed by National Laboratory for Civil Engineering of Portugal and optimized for the climate of the Iberian Peninsula.

These indicators have been calculated from the values obtained in each of the environmental measurement points (A points) of Fig. 3, using these to calculate the average value of each classroom under study, as well as standard deviation.

\section{ANALYSIS OF RESULTS}

Following the methodology described, the results are grouped into three sections:

- Objective thermal parameters.

- Occupants' clothing thermal insulation.

- Thermal environment evaluation.

\section{A. Objective Thermal Parameters}

Mean objective parameters obtained during the week under study are shown in Table IV. As can be seen, the mean number of occupants in this period is close to 20 , with a mean age of students of 16 years and a $52 \%$ of female students. The mean thermal insulation for clothing is $0.98 \mathrm{clo}$, close to the winter value described in EN ISO 7730.

The HVAC system only operates during the last day $(9,10$ and 11 lessons under measurement), being the classroom in free-running the other days. Despite of this, windows are opened just in $27 \%$ of the measurements, increasing to $37.5 \%$ if only free-running instants are considered. Lighting system was in operation during all the measurements.

TABLE IV: MEAN OBJECTIVE PARAMETER VALUES IN CLASSROOM 24 BETWEEN $15^{\mathrm{TH}}$ NOVEMBER $-21^{\mathrm{ST}}$ NOVEMBER

\begin{tabular}{|c|c|c|c|c|c|c|c|c|c|c|c|c|c|}
\hline Lesson under measurement & 1 & 2 & 3 & 4 & 5 & 6 & 7 & 8 & 9 & 10 & 11 & Mean & $\sigma$ \\
\hline Day / Instant of measurement & $1 / 1$ & $1 / 2$ & $2 / 1$ & $2 / 2$ & $2 / 3$ & $2 / 4$ & $3 / 1$ & $3 / 3$ & $4 / 1$ & $4 / 2$ & $4 / 3$ & - & - \\
\hline No. of students & 14 & 12 & 17 & 16 & 21 & 15 & 11 & 16 & 21 & 16 & 13 & 17.64 & 3.23 \\
\hline No. of teachers & 2 & 2 & 2 & 2 & 2 & 2 & 2 & 2 & 2 & 2 & 2 & 2.00 & 0.00 \\
\hline Mean age (years) & 16 & 17 & 17 & 17 & 16 & 17 & 16 & 16 & 15 & 16 & 16 & 16.37 & 0.50 \\
\hline Mean gender $(\mathrm{M} / \mathrm{F}, 0$ to 1$)$ & 0.50 & 0.57 & 0.42 & 0.44 & 0.52 & 0.53 & 0.54 & 0.39 & 0.43 & 0.39 & 0.53 & 0.48 & 0.07 \\
\hline Mean clothing insulation (clo) & 0.93 & 0.87 & 0.92 & 0.84 & 1.02 & 0.88 & 1.17 & 1.03 & 0.99 & 0.97 & 1.16 & 0.98 & 0.30 \\
\hline HVAC operation (No/Yes) & No & No & No & No & No & No & No & No & Yes & Yes & Yes & 0.27 & 0.47 \\
\hline Windows opened (No/Yes) & No & No & No & No & Yes & Yes & No & Yes & No & No & No & 0.27 & 0.47 \\
\hline Lighting (Off/On) & On & On & On & On & On & On & On & On & On & On & On & 100 & 0 \\
\hline Outdoor temperature $\left({ }^{\circ} \mathrm{C}\right)$ & 15.5 & 16.1 & 16.8 & 20.1 & 22.0 & 14.1 & 12.1 & 16.6 & 16.2 & 17.8 & 18.4 & 16.9 & 2.7 \\
\hline Mean air temperature $\left({ }^{\circ} \mathrm{C}\right)$ & 20.7 & 21.5 & 20.2 & 21.1 & 22.7 & 21.2 & 20.3 & 21.8 & 19.6 & 20.1 & 20.3 & 20.8 & 0.9 \\
\hline Mean radiant temperature $\left({ }^{\circ} \mathrm{C}\right)$ & 20.9 & 20.8 & 22.1 & 21.9 & 22.9 & 20.7 & 20.5 & 20.6 & 22.1 & 21.5 & 21.2 & 21.5 & 1.0 \\
\hline Mean relative humidity (\%) & 71.8 & 75.3 & 66.4 & 61.5 & 60.0 & 62.7 & 64.1 & 70.1 & 55.1 & 52.8 & 50.9 & 62.6 & 7.9 \\
\hline
\end{tabular}

Regarding to indoor air temperature, it oscillates between 19 and $23{ }^{\circ} \mathrm{C}$ with the classroom occupied, despite outdoor temperature has a mean value of $17^{\circ} \mathrm{C}$. It is also possible to see the influence of the HVAC system in the air temperature during the last day, since, given that the high air volume introduced into the room $(7.5 \mathrm{ACH})$ constantly renovates this indoor air preventing its temperature increase. Mean radiant temperature values tend to be about $0.6^{\circ} \mathrm{C}$ higher than indoor air temperature, and relative humidity is $65.6 \%$, but increasing to $66.5 \%$ when the HVAC system is off and descending to $52.9 \%$ when it is operating.

\section{B. Occupants' Clothing Thermal Insulation}

The occupants' mean thermal insulation for clothing during the measurements is 0.98 clo (mean operative temperature of $21.2^{\circ} \mathrm{C}$ ), with a standard deviation of $\pm 0.30 \mathrm{clo}$, as can be seen in Fig. 4. When gender is included, female occupants wear clothes with higher thermal insulation than male occupants do, about 0.07 clo, also having a slightly higher deviation. In addition, just $50 \%$ of the women under study has a clothing insulation lower than 0.90 clo, while more than $65 \%$ of male occupants do.

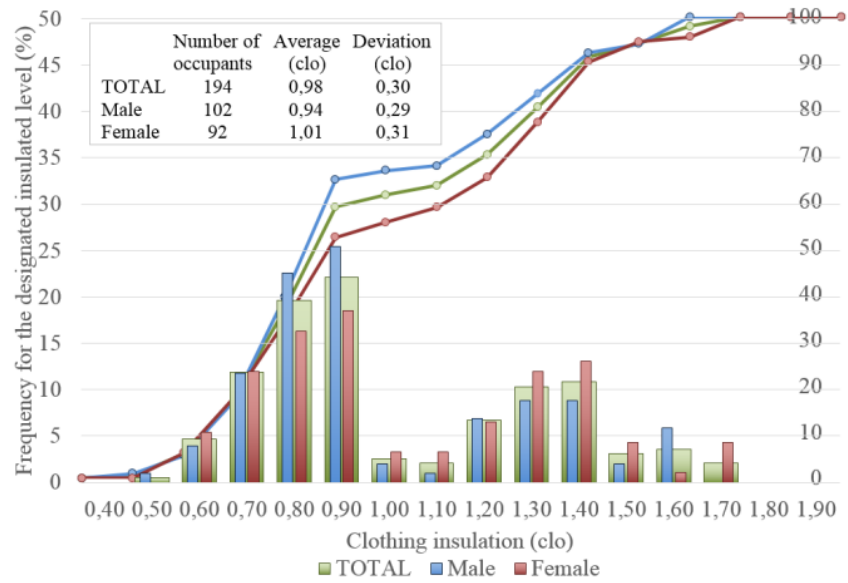

Fig. 4. Distribution of the clothing insulation level.

Furthermore, and as seen in Fig. 5, the thermal insulation of clothing can be individually compared with its respective operative temperature value, using IREQ ${ }_{\min }$ and $I_{R E Q_{\text {neu }}}$ for establishing limits of the recommended insulation level area. It shows that the vast majority of occupants wears clothes with a higher thermal insulation value than the minimum required for maintaining thermal equilibrium with high physiological response $\left(I R E Q_{\text {min }}\right)$, also varying around the required clothing insulation value for maintaining thermal equilibrium without 
physiological response (IREQ $\left.{ }_{\text {neu }}\right)$. Nevertheless, none matches this value, since they mainly tend to wear clothes with a lower thermal insulation level of 0.7-0-9 clo (without coat or jackets), and to a lesser extent of 1.2-1.5 clo (with coat or jacket).

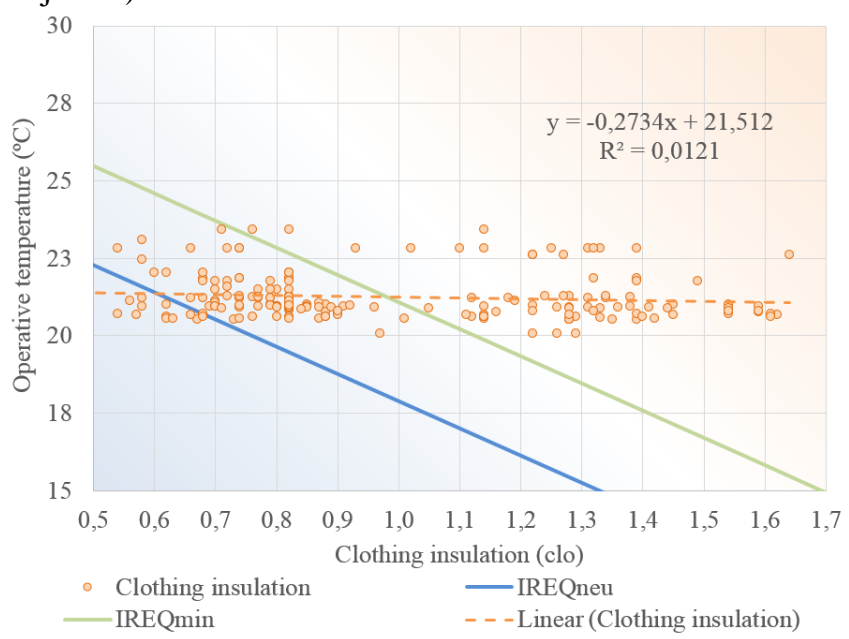

Fig. 5. Clothing insulation level according to operative temperature.

\section{Thermal Environment Evaluation}

Mean thermal indicator values, calculated with collected surveys and objective thermal parameters performed during the week under study, are shown in Table V. The mean Predicted Mean Vote (PMV) value is -0.39 , category B (comfort) according to EN-ISO 7730 with a standard deviation of \pm 0.22 . However, the Thermal Sensation Vote
(TSV) expressed by the occupants qualifies the mean thermal environment as neutral (-0.03) with a standard deviation of \pm 0.55 , which shows a category A and a difference of more than 0.40 points in a 7-points ASHRAE scale of -3 to +3 , despite of the higher deviation (more than twice of the PMV).

By contrast, the mean Thermal Preference Vote (TPV) is more than 0.65 points higher of TSV, also having a lower standard deviation $( \pm 0.37)$, which shows a higher preference for warmth when this environment is found as neutral (comfortable).

When stratification phenomena are studied through cold feet/hot face assessments, it is possible to see a pronounced mean perception of cold feet, about $40 \%$, with a lower but significant perception of hot face, about $22 \%$, which shows a high perception of stratification phenomena, despite of the general occupant's mean environment thermal acceptance of $85 \%$.

In the case of the occupants' mean environment thermal acceptance, it is about $85 \%$, being in general above this value but when HVAC is operating. Matias's adaptive thermal comfort indicator obtains similar mean values, about $90.5 \%$, while ASHRAE adaptive thermal comfort indicator shows significantly lower values, $27.3 \%$ of theoretically satisfied occupants. Therefore, Matias' adaptive thermal indicator achieves for this case of study a better approximation to occupants' thermal acceptance than PMV and ASHRAE 55 indicators.

TABLE V: MEAN THERMAL INDICATOR VALUES IN CLASSROOM 24 BETWEen $15^{\text {TH }}$ NOVEMBER $-21^{\text {ST }}$ NOVEMBER

\begin{tabular}{|c|c|c|c|c|c|c|c|c|c|c|c|c|c|}
\hline Lesson under measurement & 1 & 2 & 3 & 4 & 5 & 6 & 7 & 8 & 9 & 10 & 11 & Mean & $\sigma$ \\
\hline Operative temperature $\left({ }^{\circ} \mathrm{C}\right)$ & 20.8 & 21.2 & 21.6 & 21.5 & 22.9 & 21.0 & 20.4 & 21.0 & 21.0 & 20.8 & 20.8 & 21.2 & 0.7 \\
\hline Predicted Mean Vote $(-3$ to +3$)$ & -0.38 & -0.29 & -0.45 & -0.54 & -0.09 & -0.57 & -0.27 & -0.21 & -0.63 & -0.69 & -0.31 & -0.39 & 0.22 \\
\hline Percentage of People Dissatisfied (\%) & 7.9 & 6.8 & 9.2 & 11.0 & 5.2 & 11.7 & 6.5 & 5.9 & 13.4 & 15.1 & 7.0 & 9.1 & 3.3 \\
\hline Thermal Sensation Vote $(-3$ to +3$)$ & 0.38 & 0.36 & -0.21 & 0.06 & 0.65 & 0.18 & 0.23 & 0.33 & -0.30 & -0.30 & -1.13 & -0.03 & 0.55 \\
\hline Thermal Preference Vote $(-3$ to +3$)$ & 0.44 & 0.36 & 0.58 & 1.00 & 0.26 & 0.35 & 0.54 & 0.28 & 0.78 & 1.06 & 1.40 & 0.64 & 0.37 \\
\hline Occupants' acceptance (\%) & 81.3 & 85.7 & 89.5 & 94.4 & 95.7 & 88.2 & 92.3 & 94.4 & 87.0 & 55.6 & 66.7 & 84.6 & 12.6 \\
\hline Cold feet $(\%)$ & 18.8 & 28.6 & 31.3 & 50.0 & 17.4 & 41.2 & 69.2 & 44.4 & 17.4 & 55.6 & 66.7 & 40.1 & 19.0 \\
\hline Hot face $(\%)$ & 31.3 & 42.9 & 26.3 & 22.2 & 52.2 & 11.8 & 30.8 & 11.1 & 4.3 & 0.0 & 13.3 & 22.4 & 16.2 \\
\hline ASHRAE thermal acceptance (\%) & 0.0 & 0.0 & 0.0 & 0.0 & 0.0 & 0.0 & 0.0 & 0.0 & 100.0 & 100.0 & 100.0 & 27.3 & 46.7 \\
\hline Matias' thermal acceptance (\%) & 100.0 & 100.0 & 100.0 & 100.0 & $\mathbf{1 7 . 4}$ & 100.0 & 100.0 & 100.0 & 78.3 & 100.0 & 100.0 & 90.5 & 25.1 \\
\hline
\end{tabular}

TABLE VI: PEARSON CORRELATION FOR MEAN THERMAL INDICATOR VALUES IN CLASSROOM 24 BETWEEN $15^{\text {TH }}$ NOVEMBER - $21^{\text {ST }}$ NOVEMBER

\begin{tabular}{|c|c|c|c|c|c|c|c|c|}
\hline Mean thermal parameter / indicator & Clo & iAT & OT & PMV & PPD & TSV & TPV & $\mathrm{OA}$ \\
\hline Clothing insulation (Clo) & 1,00 & $-0,18$ & $-0,26$ & 0,39 & $-0,39$ & $-0,30$ & 0,24 & $-0,17$ \\
\hline Indoor air temperature (iAT) & - & 1,00 & 0,68 & 0,73 & $-0,59$ & 0,67 & $-0,58$ & 0,48 \\
\hline Operative temperature (OT) & - & - & 1,00 & 0,54 & $-0,28$ & 0,42 & $-0,32$ & 0,42 \\
\hline Predicted Mean Vote (PMV) & - & - & - & 1,00 & $-0,92$ & 0,53 & $-0,46$ & 0,44 \\
\hline Percentage of People dissatisfied (PPD) & - & - & - & - & 1,00 & $-0,49$ & 0,43 & $-0,46$ \\
\hline Thermal Sensation Vote (TSV) & - & - & - & - & - & 1,00 & $-0,90$ & 0,80 \\
\hline Thermal Preference Vote (TPV) & - & - & - & - & - & - & 1,00 & $-0,66$ \\
\hline Occupants' acceptance (OA) & - & - & - & - & - & - & - & 1,00 \\
\hline
\end{tabular}

If Pearson correlations are calculated between the main thermal indicators, as shows Table VI, it is possible to find a lower correlation between clothing insulation and the rest of mean indicators under study $(<0.40)$. Nevertheless, it is noteworthy to mention the medium relationship of the indoor air temperature with TSV (positive, 0.67) and TPV (negative,
-0.58) indicators; however, a lower relationship appears when comparing operative temperature with TSV (positive, 0.42) and TPV (negative, -0.32), which suggests a higher connection of these perceptions with air temperature than with mean radiant temperature. 


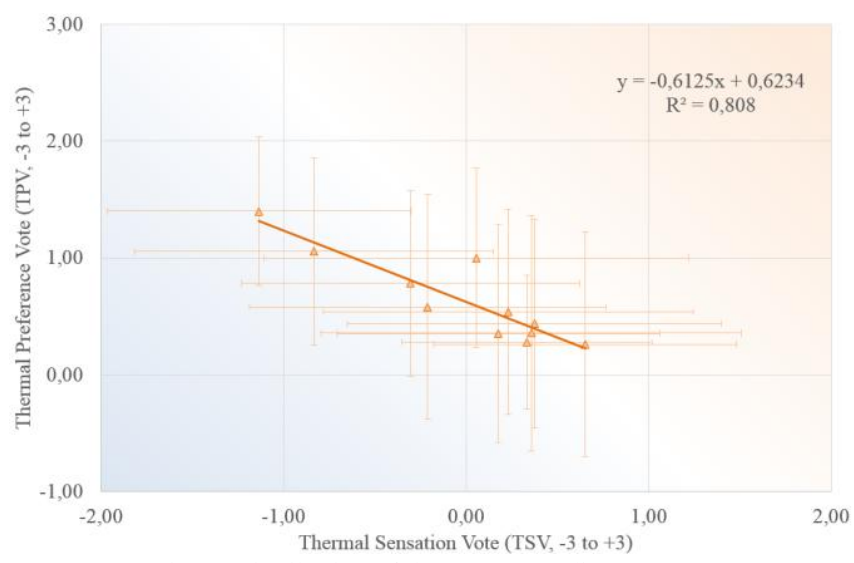

Fig. 6. Distribution of the TSV according to TPV.

When the connection between mean TSV and mean TPV is analysed for the classroom under study, a very high correlation appears (negative, 0.90), which can be expressed as a linear equation $\left(\mathrm{R}^{2}=0.80\right)$, as can be seen in Fig. 6 . This graph also shows the occupants' higher preference for warmth with respect to their thermal sensation perceived.

In addition, the analysis of the connection between mean TSV and occupants' mean thermal acceptance shows a high correlation (positive, 0.80), so it is possible to express this relationship through an exponential equation $\left(\mathrm{R}^{2}=0.59\right)$, as is presented in Fig. 7.

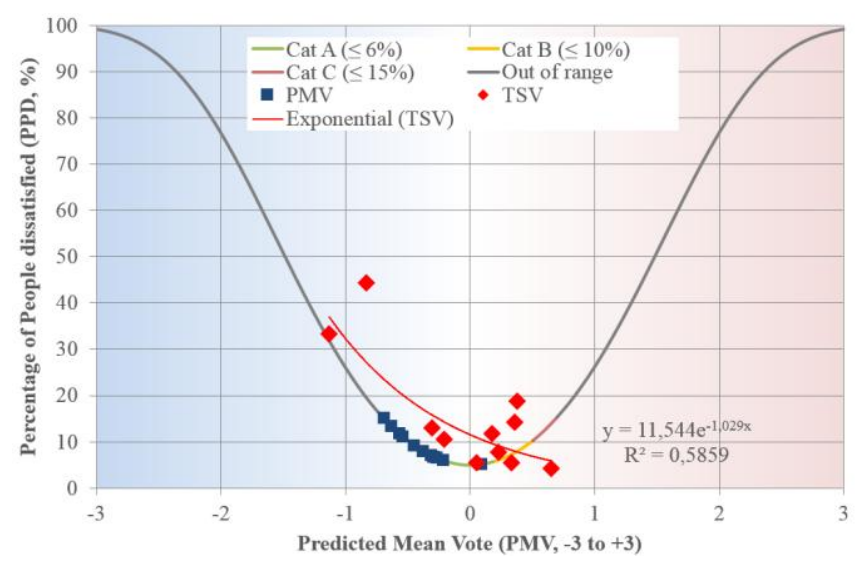

Fig. 7. Distribution of PMV and TSV according to PPD.

This graph shows a displacement between the PMV and TSV curves, despite of the low quantity of values included in this study; this deviation is due to the occupants' perception, which find the environments as warmer than PMV results.

In this way, it can be suspected that occupants of the south of the Iberian Peninsula are generally used to be out of thermal comfort conditions in their homes, probably due to the low thermal insulation level of their traditional envelopes and the poor use of heating systems [36]-[39]. Hence, these points act as social and psychological factors that can affect the occupants' thermal perceived sensation, so further research is required.

When studying the distribution of the TSV in the classroom under study, it is concluded that it takes the shape of a Gaussian curve around a mean value of -0.02, as shows Fig. 8 . It can be seen in this graph that more than $80 \%$ of occupants have a sensation vote between -1 and +1 , as well as the difference between genders is not remarkable, being less than 0.02 .

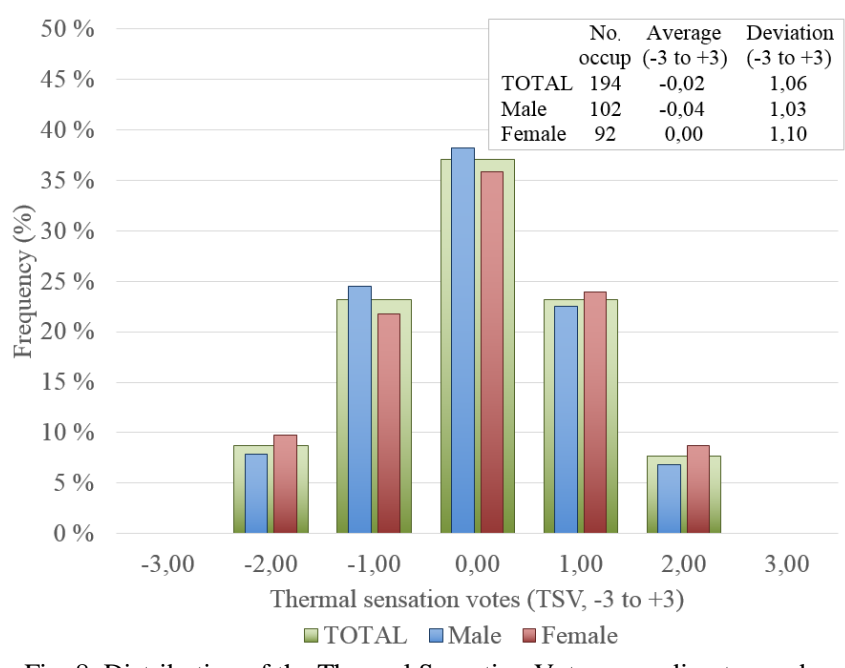

Fig. 8. Distribution of the Thermal Sensation Votes according to gender.

Nevertheless, when distribution of TPV is analysed, a higher preference for warmth with respect to the thermal perceived sensation appears, as showed the previous comparison between TSV and TPV. As can be seen in Fig. 9, almost $60 \%$ of the occupants demand a warmer environment, compared with $33 \%$ who prefer to continue in the same conditions and $8 \%$ who demand a cooler environment.

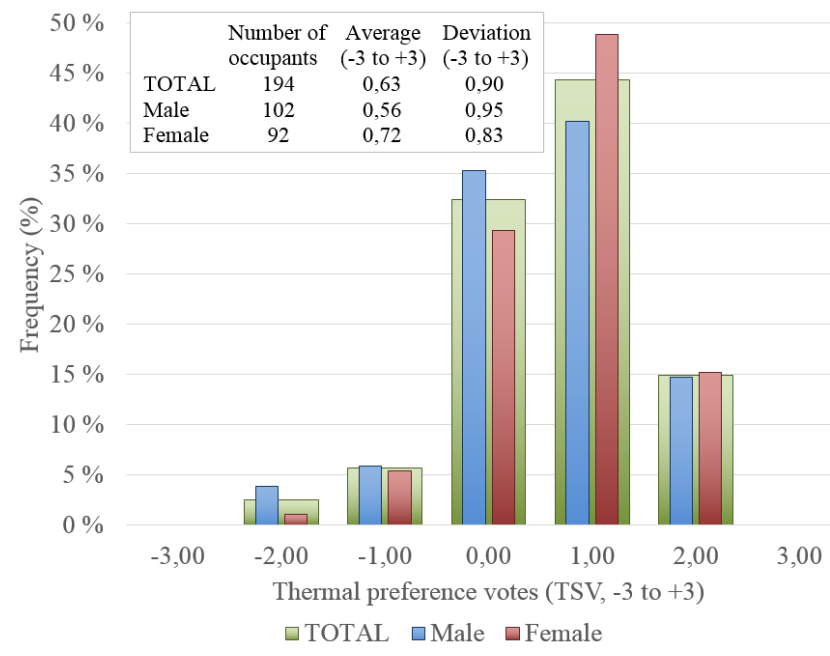

Fig. 9. Distribution of the thermal preference votes according to gender.

If gender is included, it is possible to see a divergence of preferences in the classroom under study, since $65 \%$ of female occupants demand a warmer environment, compared with $55 \%$ of male occupants; in addition, just $30 \%$ of women prefer to continue in the same conditions with regard to $35 \%$ of men.

This divergence also can be found when TSV is related to thermal acceptance, as shows Fig. 10; there is a higher rejection of environments perceived as cold $(7.22 \%)$ than for perceived as warmth $(3.09 \%)$, as well as a higher acceptance of environments perceived as warmth (4.64 \%) than for perceived as cold $(1.55 \%)$.

When gender is added to this occupants' thermal acceptance analysis, it is possible to see that male occupants tend to find neutral and slightly cool/warm environments as a little bit more acceptable than female occupants, also finding warm environments as less acceptable than female occupants, who additionally rejected all the environments perceived as 
cold during this study.

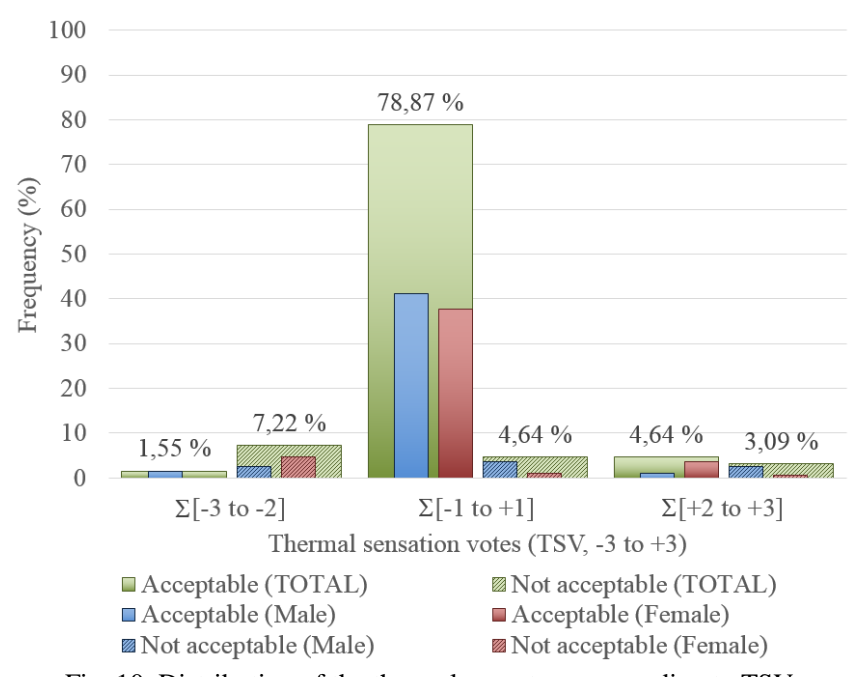

Fig. 10. Distribution of the thermal acceptance according to TSV.

\section{Conclusions}

A comprehensive thermal analysis has been carried out in a multipurpose classroom of a Portuguese secondary school during a week of November, as a methodological example. Hygrothermal parameters were measured while parallel subjective surveys were collected, calculating both static and adaptive thermal comfort indicators.

Occupants perceived a neutral thermal environment (TSV value of -0.03 in the 7-points ASHRAE scale) in the classroom under study, existing a remarkable deviation in their opinions expressed (about \pm 0.55 ). This thermal sensation is not equivalent to the thermal preference expressed, since they demand a warmer environment (TPV mean value of +0.64$)$. Despite this displacement, these two mean votes are strongly interrelated, since there is a very high negative linear correlation between them (-0.90). If gender is added as an analysis factor for both perceptions, it can be seen that TSV shows no relevant differences between male and female occupants. But in the case of TPV, female occupants have a higher preference for warmth than male occupants, since $65 \%$ of female occupants demand a warmer environment, compared with $55 \%$ of male occupants, as well as just $30 \%$ of women prefer to continue in the same conditions with regard to $35 \%$ of men.

In the case of the occupants' mean environment thermal acceptance, it is about $85 \%$ despite of the high perception of stratification phenomena. This acceptance is also somewhat higher for environments perceived as warmth, especially in the case on female occupants, who additionally rejected all the environments perceived as cold during this study.

When thermal environmental perceptions are compared with the values obtained from calculated thermal comfort indicators, it is possible to see that the perceived sensation (TSV) is higher than the Predicted Mean Vote (PMV) static indicator in 0.35 points, so PMV indicator underestimates TSV. Despite of this, when the relationship between them is analysed, a medium correspondence can be found, with a Pearson correlation of 0.53 . This difference could be due to the influence of psychological and social factors related to the low thermal insulation level of dwellings traditional envelopes and the low use of heating systems.

Finally, the comparison of both ASHRAE and Matias' adaptive thermal comfort indicators with occupants' thermal acceptance votes shows that Matias' model obtains similar mean values $(90.5 \%)$ than the occupants' assessment (about $85 \%$ ), while ASHRAE adaptive thermal comfort indicator shows significantly lower values $(27.3 \%)$. Therefore, it can be concluded that, for this case of study, Matias' adaptive thermal indicator achieves a better approximation to occupants' thermal acceptance than PMV and ASHRAE 55 indicators, so further investigation is required.

\section{ACKNOWLEDGMENT}

The authors wish to express their gratitude to Jaime Costa-Luque for reviewing the manuscript and helping with several of the graphics, as well as to the students, teachers and management team of the "Eça de Queirós" secondary school educational community. Finally, to the Public Entity "Parque Escolar" from the Government of Portugal.

\section{REFERENCES}

[1] F. C. Houghten and C. P. Yagloglou, "Determination of comfort zone," ASHVE Trans., vol. 29, pp. 349-361, 1923.

[2] J. Andersson, A. Boerstra, D. Clements-Croome, K. Fitzner, and S. O. Hanssen, Indoor Climates and Productivity in Offices, Brussels: REHVA, 2006, no. 6.

[3] M. J. Mendell and J. A. Heath, "Do indoor pollutants and thermal conditions in schools influence student performance? A critical review of literature," Indoor Air, vol. 17, no. 1, pp. 2-18, Feb 2005.

[4] V. D. Giuli, O. D. Pos, and M. D. Carli, "Indoor environmental quality and pupil perception in Italian primary schools," Build Environ, vol. 56, pp. 335-354, Mar. 2012.

[5] W. R. Lane, Education, Children and Comfort, Iowa: University of Iowa, 1965.

[6] A. Auliciems, "Thermal sensations of secondary school children in summer," J Hyg-Cambridge, vol. 71, pp. 453-458, Sep 1973.

[7] M. A. Humphreys, "A study of the thermal comfort of primary school, children in summer," Build Environ, vol. 12, no. 4, pp. 231-239, Apr 1977.

[8] R. D. Pepler, "The thermal comfort of students in climate-controlled and non-climate-controlled schools," ASHRAE Trans, vol. 78, no. 1, pp. $97-109,1972$.

[9] S. Mors, J. L. M. Hensen, M. G. L. C. Loomans, and A. C. Boerstra, "Adaptive thermal comfort in primary school classrooms: Creating and validating PMV-based comfort charts," Build Environ, vol. 46, pp. 2454-2461, Dec 2011.

[10] P. Fanger, Thermal Comfort: Analysis and Applications in Environmental Engineering, Copenhagen: Copenhagen Danish Technical Press, 1970.

[11] American Society of Heating Refrigerating and Air Conditioning Engineers, ASHRAE Handbook: Fundamentals, Atlanta: ASHRAE, 2009.

[12] S. P. Corgnati, R. Ansaldi, and M. Filippi, "Thermal comfort in Italian classrooms under free running conditions during mid-seasons: Assessment through objective and subjective approaches," Build Environ, vol. 44, pp. 785-792, Apr 2009.

[13] K. Fabbri, "Thermal comfort evaluation in kindergarten: PMV and PPD measurement through datalogger and questionnaire," Build Environ, vol. 68, pp. 202-214, Oct 2013.

[14] V. De Giuli, R. Zecchim, L. Corain, and L. Salmaso, "Measured and perceived environmental comfort: Field monitoring in an Italian school," Appl Ergon, vol. 45, no 4, pp. 1035-1047, Jul 2014.

[15] D. Teli, M. F. Jentsch, and P. A. B. James, "Naturally ventilated classrooms: An assessment of existing comfort models for predicting the thermal sensation and preference of primary school children," Energ Buildings, vol. 53, pp. 166-182, Oct 2012.

[16] D. Teli, P. A. B. James, and M. F. Jentsch, "Thermal comfort in naturally ventilated primary school classrooms," Build Res Inf, vol. 41, no. 3, pp. 301-316, Apr 2013. 
[17] Y. Hyunjun, N. Insick, K. Jinman, Y. Jinho, L. Kyoungho, and S. Jongryeul, "A field study of thermal comfort for kindergarten children in Korea: An assessment of existing models and preferences of children," Build Environ, vol. 75, pp. 182-189, May 2014.

[18] P. O. Fanger and J. Toftum, "Extension of the PMV model to non-air-conditioned buildings in warm climates," Energ Buildings, vol. 34, pp. 533-536, 2002.

[19] F. R. d'Ambrosio-Alfano, E. Ianniello, and B. I. Palella, "PMV-PPD and acceptability in naturally ventilated schools," Build Environ, vol. 67, pp. 129-137, May. 2013.

[20] G. S. Brager and R. J. de Dear, A standard for natural ventilation, ASHRAE J., vol. 42, no. 10, pp. 21-8, 2000.

[21] K. J. McCartney and J. F. Nicol, "Developing an adaptive algorithm for Europe," Energ Buildings, vol. 34, pp. 623-635, July 2002.

[22] J. F. Nicol and M. A. Humphreys, "Derivation of the adaptive equations for thermal comfort in free-running buildings in European standard EN15251,” Build Environ, vol. 45, pp. 11-17, Jan. 2010.

[23] Thermal environmental conditions for human occupancy, ASHRAE Standard 55, 2010

[24] Indoor environmental input parameters for design and assessment of energy performance of buildings addressing indoor air quality, thermal environment, lighting and acoustics, CEN Standard EN 15251-2007.

[25] M. Kottek, J. Grieser, C. Beck, B. Rudolf, and F. Rubel, "World Map of the Köppen-Geiger Climate Classification Updated," Meteorol Z, vol. 15, pp. 259-263, June 2006.

[26] Ventilation for buildings, Design criteria for the indoor environments, CR Standard 1752-1998.

[27] M. A. Campano, J. J. Sendra, and S. Domínguez-Amarillo, "Analysis of Thermal Emissions from Radiators in Classrooms in Mediterranean Climates," Procedia Eng, vol. 21, pp. 106-113, Feb. 2011.

[28] M. A. Campano, "Confort térmico y eficiencia energética en espacios con alta carga interna climatizados: Aplicación a espacios docentes no universitarios en Andalucía," PhD Dissertation, Dept. of Building Construction I, Sevilla Univ., Sevilla, Spain, 2015.

[29] Ergonomics of the Thermal Environment, Instruments for Measuring Physical Quantities, ISO Standard 7726-2002.

[30] Hot environments. Estimation of the heat stress on working man, based on the WBGT-INDEX (Wet Bulb Globe Temperature), ISO Standard 7243-1989.

[31] Ergonomics of the Thermal Environment. Analytical determination and interpretation of thermal comfort using calculation of the PMV and PPD indices and local thermal comfort criteria, ISO Standard 7730-2005.
[32] Ergonomics of the thermal environment - Determination and interpretation of cold stress when using required clothing insulation (IREQ) and local cooling effects, ISO Standard 11079-2009.

[33] C. E. A. Winslow, L. P. Herrington, and A. P. Gagge, "Physiological reactions to environmental temperature," Am J Physiol, vol. 120, pp. 1-22, Aug 1937.

[34] M. C. Guedes, L. Matias, and C. P. Santos, "Thermal comfort criteria and building design: field work in Portugal," Renew Energ, vol. 34, no. 11, pp. 2357-2361, Nov. 2009.

[35] L. Matias, Desenvolvimento de um modelo adaptativo para definição das condições de conforto térmico em Portugal, Lisboa: Coleção Teses e Programas de Investigação LNEC, 2010.

[36] J. J. Sendra, S. Domínguez-Amarillo, P. Bustamante, and A. L. León, "Energy intervention in the residential sector in the south of Spain: Current challenges," Inf Constr, vol 65, no. 523, pp. 457.464, Oct. 2013.

[37] S. Dominguez-Amarillo, J. Fernández-Agüera, J. J. Sendra, and J. Arroyo, "Methodology for the analysis of energy and water performance in social housing: its application in the case of Malaga,' Proc. Obsolescence and Renovation. 20th Century Housing in the New Millenium, 2015, pp. 264-268.

[38] J. Fernández-Aguera, J. J. Sendra, R. Suárez, S. Domínguez-Amarillo, and I.Oteiza, "Correlation between airtightness and IAQ in subsidized Dwellings units in Spain," in Proc. 36th AIVC 5th TightVent \& 3rd venticool Conference, 2015, pp. 86-89.

[39] S. Domínguez-Amarillo, "Building envelopes and social housing in Southern Europe energy assessment of the residential social stock of the city of Seville under the Climate Change scenario," $\mathrm{PhD}$ dissertation, Dept. of Building Construction I, Sevilla Univ., Sevilla, Spain, 2016.

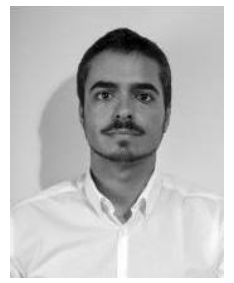

M. A. Campano is a $\mathrm{PhD}$ researcher at the Department of Building Construction I, University of Seville, Spain. He is a member of the research group TEP-130, which is focused on sustainability, energy efficiency, lighting, acoustics and optics related to building design and heritage refurbishment.

He develops research on the field of energy efficiency, indoor environmental comfort and architectural design daylighting, as well as their relationship with the 